\title{
Back Pain in Poland and Germany: A Survey of Prevalence and Association with Demographic Characters
}

\author{
Lea Henn, ${ }^{1}$ Katarzyna Schier, ${ }^{2}$ Tamara Brian, ${ }^{1}$ and Jochen Hardt ${ }^{1}$ \\ ${ }^{1}$ Medical Psychology and Medical Sociology, Clinic for Psychosomatic Medicine and Psychotherapy, School of Medicine, \\ Johannes Gutenberg University, Duesbergweg 6, 55128 Mainz, Germany \\ ${ }^{2}$ Faculty of Psychology, University of Warsaw, Ulica Stawki 5/7, 00-183 Warsaw, Poland
}

Correspondence should be addressed to Jochen Hardt; jochen.hardt@gmx.de

Received 18 February 2014; Revised 17 June 2014; Accepted 17 June 2014; Published 1 July 2014

Academic Editor: Sebastian Straube

Copyright (C) 2014 Lea Henn et al. This is an open access article distributed under the Creative Commons Attribution License, which permits unrestricted use, distribution, and reproduction in any medium, provided the original work is properly cited.

\begin{abstract}
Background. Back pain is the most common form of pain and leads to high costs in all medical care systems. Objective. The present study examines the prevalence of back pain and its associations with some basic demographics. Methods. Two samples from Poland and Germany (about $n=500$ each) were examined via Internet regarding back pain, gender, age, and body mass index (BMI). Results. Back pain is more common in women than in men (risk ratio about 1.7), and a high BMI constitutes an additional risk factor. Age was not related to back pain prevalence. Conclusion. Congruent results in two countries based on the same measure of back pain lead to the assumption that much of the variety found in estimates of back pain are due to inconsistent assessment. For future research, a definition of common criteria on how to assess back pain would be an asset.
\end{abstract}

\section{Introduction}

Back pain is the most prevalent pain; estimates say that about $9.4 \%$ of the global population are severely affected [1]. It ranks at least since 1990 and till 2010 on the first place for the years lived with disability [2]. Back pain accounts for enormous health care costs: estimates for Germany were about $€ 7000$ per year on per affected patient basis or $€ 1322$ per person and year based on the population (data from 2004/5: $[3,4]$ ). More than half of these costs are due to absence from work; other costs result from treatment and rehabilitation. Costs due to early retirement were not included in the calculations; however, data from 2012 show that back pain (and other musculoskeletal disorders) is the reason for only approximately $12 \%$ of the cases of early retirement nowadays [5]. Even higher costs were reported from the USA, where annual costs resulting from chronic lower back pain patients were estimated at almost $\$ 12,000$ for medical care alone, with a large proportion coming from in- and outpatient service [6]. The problem of back pain may even increase in future, since members of the western population are showing a decrease in physical activity and an increase in weight over the years (e.g., [7]).

A search in the Cochrane database in January 2014 utilizing the term "chronic back pain" yielded 61 reviews, 19 of those were withdrawn, were protocols, or did not primarily deal with chronic back pain. The remaining 42 reviews cover a wide range of treatments, for example, total disk replacement, radiofrequency denervation, various drugs taken orally or being injected, lumbar support, transcutaneous electric nerve stimulation, traction, physical conditioning, back school, cognitive behavioral therapy, and various more. The essence of the reviews does not provide much hope for back pain patients; most therapies are either not effective in the long term, have side effects, or show little or conflicting evidence to support their effectiveness. Effect sizes generally were small. For clinical practice, this means that the best therapy for each patient needs to be determined individually, and, particularly, for nonspecific back pain, there are not many evidence based recommendations available (e.g., [8]).

Data from the USA indicate that, in practice, treatment mostly includes or even solely relies on pain killers (about 
$70 \%$ of the patients). In the USA weak opioids have been prescribed against back pain more and more since the mid1990 s. In the USA, about $40 \%$ of back pain patients sometimes take opioids with strong regional variation [9]. Fortunately, opioid use is less frequent in Europe-only about 25\% of chronic back pain patients take them [10]. Other than clinical experience, there is no scientific evidence that opioids work better than other pain killers for moderate back pain [11, 12]. Since 2005, deaths due to prescribed opioids have outnumbered the deaths due to illegal drugs on the street in the USA [13]. It is unclear whether a similar development will occur in Europe. The recommended alternatives here are mostly nonsteroidal anti-inflammatory drugs (NSAID). However, NSAIDs should not be used against back pain for a period longer than three months [8].

Strong reliance on drug therapy for treating back pain is not necessarily optimal. Airaksinen provides a more positive overview than the Cochrane reviews. When back pain becomes chronic, multidisciplinary treatment shows much better results than one-track treatment with pain killers [8]. Multidisciplinary treatment can reach 6-month pre-post effect sizes for pain reduction of about $d=0.8$; as long as there is no wish for early retirement, the effect is zero or even negative [14]. Also, back pain patients can develop medication overuse headache and in the long term pain killers do not lead to much success in back pain treatment. In the long run, surgical interventions show high rates of complications or nonsuccess. Such considerations have led some professionals to rethink traditional back pain treatment in western medical systems and, for example, suggest incorporating physiotherapists much earlier [15]. A small study comparing 15 patients against controls who trained for ten weeks only two minutes per day showed a promising reduction of back and neck pain [16].

The central aim of the present investigation is to explore the prevalences of back pain in Poland and Germany and their associations with age, gender, and body mass index (BMI).

\section{Material and Methods}

2.1. Sample. The analysis was performed on two Internet surveys of 508 subjects in Poland and 500 in Germany. Participants who were registered at a professional marketing company received an email which invited them to take part in the survey (http://www.linequest.de/). The questionnaire set contained about 280 items and participants received compensation of about $€ 4,30$ for filling out the questionnaire. The Ethics Commissions of the University of Düsseldorf (2873) and the Landesärztekammer Rheinland-Pfalz approved the project (837.185.07). During data collection, information was displayed at the University of Mainz in German and Poland verifying the scientific background of the study. Demographic data from the samples are displayed in Table 1.

2.2. Variables. The central variable "back pain" was assessed via one item of the "symptom check list 27 plus," a questionnaire designed by Hardt $[17,18]$. Back pain is one of 20 symptoms whose occurrence in general was assessed.
The answer was a five-point Likert scale containing the categories "never," "rarely," "sometimes," "often," or "very often." For the present study, the variable was dichotomized; that is, "never," "rarely," and "sometimes" were counted as no back pain and "often" or "very often" as back pain. The rationale behind the dichotomization was to yield a simple response variable, which (a) reflects the subjects suffering mostly under back pain and (b) allows for complex tests of predictors. We did not consider aspects as precise location, that is, upper or lower back pain, pain in limbs associated with the back pain, or duration.

Age, gender, weight, and height were ascertained; BMI was calculated as $\mathrm{kg} / \mathrm{m}^{2}$. Since the distribution of the BMI had serious outliers to the right, it was coded into four categories, as displayed in Table 1. Two subjects who had missing data on BMI were allotted to the group $\mathrm{BMI} \leq 25$.

2.3. Statistics. A logistic regression analysis was performed on the response variable back pain. Beside the four main effects, all two-way interactions as well as quadratic effects for age and BMI were tested. First, a backward selection of the main effects was performed. Second, the respective interaction and quadratic effect were tested always including all underlying main effects [19]. In case of a quadratic effect, the test had two degrees of freedom (df) in the nominator; while in case of an interaction, there were three df. Significance was set to alpha $=0.01$ in order to avoid statistically significant but clinically nonsignificant results. No trends were interpreted. The analysis was performed using Stata [20]. The significant predictors were presented in a graph.

\section{Results}

In Poland, a total of $22.6 \%$ reported to have often or very often back pain, whereas in Germany the corresponding prevalence rate was even $28.8 \%$. Table 1 shows the comparisons of the samples from Poland and Germany in detail. Polish participants were about six years younger on average than the German ones, had a higher BMI, and were more often married and a higher professional status was reported. Other differences were small and did not reach significance. Table 2 shows the result of the logistic regression analysis. Two predictors for back pain could be identified: gender and BMI. The gender effect was strong and explained about $2 \%$ of the variance in the logistic regression. Women were more likely to report back pain than men. The effect for BMI was relatively small and explained only $0.75 \%$ of variance. However, the direction is plausible: the higher the BMI, the higher the likelihood for reported back pain. There was no interaction between gender and BMI; the $P$ value was 0.237 . Accordingly, Figure 1 displays the two main effects, not including the interaction effect. No other effects reached significance. The closest value would have been the main effect for country $(P=0.029)$.

\section{Discussion}

The prevalence of back pain is higher in our estimate than in others. For example, Hoy et al. [1] estimated a prevalence of 
TABLE 1: Demographics.

\begin{tabular}{|c|c|c|c|c|}
\hline Variable & $N=508$ & $N=500$ & & $P$ \\
\hline Country & Poland & Germany & \multirow{3}{*}{$\begin{array}{c}\chi_{(1)}^{2}=4.02 \\
t=6.61\end{array}$} & \\
\hline Sex (\% female) & 56.30 & 50.00 & & 0.045 \\
\hline Age: $\bar{x}(\mathrm{sd})$ & $38.7(14.4)$ & $44.8(17.1)$ & & $<0.001$ \\
\hline \multicolumn{5}{|l|}{ Body mass index (\%) } \\
\hline$\leq 25.00$ & 55.9 & 44.4 & \multirow{4}{*}{$\chi_{(3)}^{2}=27.75$} & \multirow{4}{*}{$<0.001$} \\
\hline $25.01-30.00$ & 32.5 & 35.0 & & \\
\hline $25.01-30.00$ & 7.7 & 15.8 & & \\
\hline$>30.00$ & 3.9 & 4.8 & & \\
\hline Back pain (\%) & 22.6 & 28.8 & $\chi_{(1)}^{2}=5.01$ & 0.025 \\
\hline \multicolumn{5}{|l|}{ Current partner in life (\%) } \\
\hline Married & 48.8 & 43.0 & \multirow{5}{*}{$\chi_{(4)}^{2}=16.71$} & \multirow{5}{*}{0.002} \\
\hline Stable relationship $>6$ months & 23.8 & 23.2 & & \\
\hline Stable relationship $\leq 6$ months & 3.5 & 3.8 & & \\
\hline No stable relationship & 17.3 & 26.6 & & \\
\hline Other & 6.5 & 3.4 & & \\
\hline \multicolumn{5}{|l|}{ Profession (\%) } \\
\hline $\begin{array}{l}\text { (I) Higher-grade professional, administrator, } \\
\text { or manager }\end{array}$ & 14.6 & 4.2 & \multirow{7}{*}{$\chi_{(6)}^{2}=80.12$} & \multirow{7}{*}{$<0.001$} \\
\hline $\begin{array}{l}\text { (II) Lower-grade professional, administrator, } \\
\text { or manager; higher-grade technician }\end{array}$ & 40.2 & 30.2 & & \\
\hline (IIIa) Skilled nonmanual employee & 18.1 & 33.0 & & \\
\hline (IIIb) Skilled manual employee & 9.2 & 5.2 & & \\
\hline (IV) Partly skilled worker & 4.7 & 10.8 & & \\
\hline (V) Unskilled labourer & 6.7 & 6.2 & & \\
\hline Others: housewife, housemen & 6.5 & 10.4 & & \\
\hline
\end{tabular}

TABLE 2: Regression analyses for "often or very often back pain.”

\begin{tabular}{|c|c|c|c|c|c|}
\hline Explanatory variable & Odds ratio & Standard error & $z$-value & $P$ value & $\Delta R^{2}$ \\
\hline \multicolumn{6}{|c|}{ Variables in the equation, pseudo $R^{2}=2.55 \%$} \\
\hline Constant & 0.11 & 0.06 & -4.48 & $<0.001$ & \\
\hline BMI & 1.05 & 0.02 & 2.95 & 0.003 & $0.75 \%$ \\
\hline Gender & 0.48 & 0.07 & -4.81 & $<0.001$ & $2.09 \%$ \\
\hline \multicolumn{6}{|c|}{ Terms not in the equation, value if added next } \\
\hline Country & 1.38 & 0.21 & 2.18 & 0.029 & $0.42 \%$ \\
\hline Age & 1.00 & 0.005 & 0.58 & 0.559 & $0.03 \%$ \\
\hline $\mathrm{Age}^{2}$ & 1.00 & 0.0003 & -0.69 & 0.490 & $0.07 \%$ \\
\hline $\mathrm{BMI}^{2}$ & 1.00 & 0.004 & -0.16 & 0.874 & $0.00 \%$ \\
\hline Country $*$ gender & 0.94 & 0.27 & -0.20 & 0.843 & $0.42 \%$ \\
\hline Country * age & 1.00 & 0.01 & 0.05 & 0.963 & $0.42 \%$ \\
\hline Country $*$ BMI & 0.98 & 0.03 & -0.53 & 0.597 & $0.44 \%$ \\
\hline Gender $*$ age & 1.00 & 0.01 & -0.07 & 0.944 & $0.03 \%$ \\
\hline Gender $*$ BMI & 0.96 & 0.04 & -1.18 & 0.237 & $0.12 \%$ \\
\hline Age $*$ BMI & 1.00 & 0.001 & 0.77 & 0.433 & $0.08 \%$ \\
\hline
\end{tabular}

about $9.4 \%$. The comparability of prevalence estimates suffers because of the various definitions of pain that exist [21]. For example, 12-month estimates for back pain were $66 \%$ for women and $58 \%$ for men [22]. Such high prevalence estimates usually include subjects with mild or moderate pain and/or relatively rare pain. So, for the present estimate, one should be aware that some participants with mild or moderate pain are included.

A central result is that women have back pain more often than men. In the low BMI group $(\leq 25)$, the point estimates were $29 \%$ and $16 \%$, so the back pain prevalence ratio between women and men is 1.8. In the highest group (BMI 40 plus), 


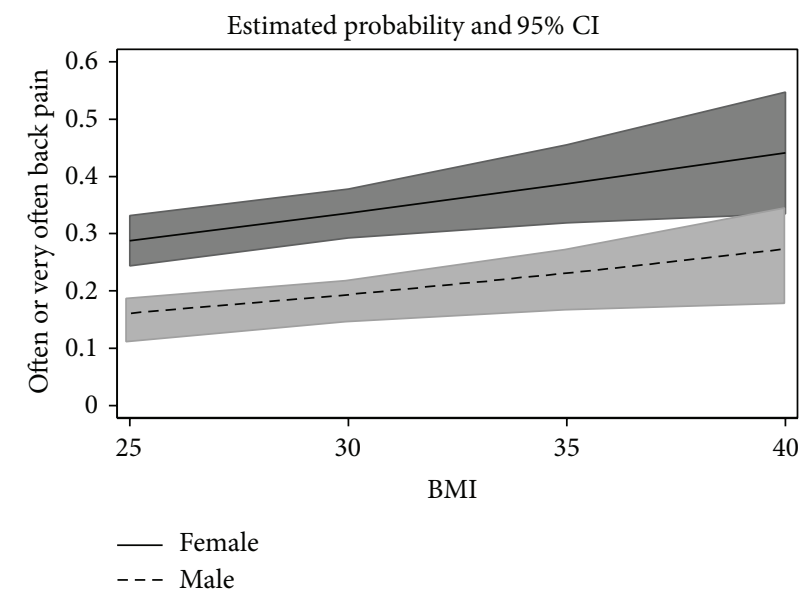

FIGURE 1: Estimated probabilities (and 95\% confidence intervals) for back pain.

the ratio was lower at 1.6 , but there is still only a minimal overlap in the confidence intervals between women and men (Figure 1). Such strong gender differences in back pain have been reported in other studies (e.g., [23]), but the average gender difference for back pain in epidemiologic studies is smaller [24]. It may be worthwhile to examine for which factors pronounced gender differences exist and for which ones they do not.

A further interesting result is the absence of any age effect in the present study. This also stands in some contrast to most other studies (e.g., [24]), where generally an increase of the back pain prevalence is seen from individuals in their 20 s compared to those in their 60 s, followed by a plateau or even decrease. Kędra and Czaprowski describe interesting data that may explain this phenomenon [25]. In youths (age 10-19) they observed no age trend when asking about back pain frequency, but a strong increase in back pain severity was observed. As possibly with gender, the various characteristics may show different associations with age.

An association of back pain with BMI is obvious, since a heavy build strains the spine. It was smaller than expected and we would have assumed an interaction of BMI with age additionally. The rationale behind this was that carrying heavy weight over a long period of time should be more destructive for the spine than a shorter time could be. This was not the case here; the $P$ value of the interaction effect was far too large to be of interest.

There was no effect for country in the present survey indicating that the same question leads to the same result in different countries, at least regarding Poland and Germany. This was shown not only for the prevalence estimate (where the difference almost reached significance), but also for the associations with gender, age, and BMI.

The present study has the following limitations. (1) Data rely on self-reports and are not verified by medical experts. (2) Data were collected via Internet surveys. It is not known how far they are representative for the population. However, there was a bias towards higher education. (3) We focus on three predictors, here, that is, age, gender, and country. Many more factors probably contribute to back pain, for example, coping [26] or behavioral factors or stress (e.g., [27]). (4) The results of this cross-sectional study do not reflect any causality. Both associations with back pain, the one for BMI and the one for gender, are likely to be mediated by various factors, for example, lack of physical exercise, diet, or genetics.

\section{Conclusion}

The present study shows congruent back pain estimates in Poland and Germany, not only regarding prevalence but also concerning associations with gender, age, and BMI. The results are partly congruent to others reported in the literature and differ in some respects. Those results underline the necessity of a common classification for back pain and preferably for other forms of pain as well (e.g., [28]).

\section{Conflict of Interests}

The authors declare that there is no conflict of interests regarding the publication of this paper.

\section{Acknowledgments}

This work was funded, in part, by the Heigl-Stiftung Düsseldorf and the Köhler-Stiftung, Essen.

\section{References}

[1] D. Hoy, L. March, P. Brooks et al., "The global burden of low back pain: estimates from the global burden of disease 2010 study," Annals of the Rheumatic Diseases, vol. 73, no. 6, pp. 968974, 2014.

[2] T. Vos, A. D. Flaxman, M. Naghavi et al., "Years lived with disability (YLDs) for 1160 sequelae of 289 diseases and injuries 1990-2010: a systematic analysis for the Global Burden of Disease Study 2010," The Lancet, vol. 380, no. 9859, pp. 21632196, 2012. 
[3] M. Juniper, T. K. Le, and D. Mladsi, "The epidemiology, economic burden, and pharmacological treatment of chronic low back pain in France, Germany, Italy, Spain and the UK: a literature-based review," Expert Opinion on Pharmacotherapy, vol. 10, no. 16, pp. 2581-2592, 2009.

[4] C. M. Wenig, C. O. Schmidt, T. Kohlmann, and B. Schweikert, "Costs of back pain in Germany," European Journal of Pain, vol. 13, no. 3, pp. 280-286, 2009.

[5] Rentenversicherung, Deutsche, "Rentenversicherung in Zahlen," 2013, http://www.deutsche-rentenversicherung.de/cae/servlet/ contentblob/238692/publicationFile/61815/01_rv_in_zahlen_ 2013.pdf.

[6] M. Gore, K. S. Tai, A. Sadosky, D. Leslie, and B. R. Stacey, "Use and costs of prescription medications and alternative treatments in patients with osteoarthritis and chronic low back pain in community-based settings," Pain Practice, vol. 12, no. 3, pp. 209-218, 2012.

[7] J. T. Lightfoot, "Why control activity? Evolutionary selection pressures affecting the development of physical activity genetic and biological regulation," BioMed Research International, vol. 2013, Article ID 821678, 10 pages, 2013.

[8] O. Airaksinen, J. I. Brox, C. Cedraschi et al., "Chapter 4: European guidelines for the management of chronic nonspecific low back pain," European Spine Journal, vol. 15, no. 2, pp. S192-S300, 2006.

[9] J. I. Ivanova, H. G. Birnbaum, M. Schiller, E. Kantor, B. M. Johnstone, and R. W. Swindle, "Real-world practice patterns, health-care utilization, and costs in patients with low back pain: the long road to guideline-concordant care," The Spine Journal, vol. 11, no. 7, pp. 622-632, 2011.

[10] H. Breivik, B. Collett, V. Ventafridda, R. Cohen, and D. Gallacher, "Survey of chronic pain in Europe: prevalence, impact on daily life, and treatment," European Journal of Pain, vol. 10, no. 4, pp. 287-333, 2006.

[11] L. E. Chaparro, A. D. Furlan, A. Deshpande, A. Mailis-Gagnon, S. Atlas, and D. C. Turk, "Opioids compared to placebo or other treatments for chronic low-back pain," The Cochrane Database of Systematic Reviews, vol. 8, Article ID CD004959, 2013.

[12] A. Deshpande, A. Furlan, A. Mailis-Gagnon, S. Atlas, and D. Turk, "Opioids for chronic low-back pain.," Cochrane Database of Systematic Reviews, no. 3, Article ID CD004959, 2007.

[13] O. Susan, "A flood of opioids, a rising tide of deaths," The New England Journal of Medicine, vol. 363, no. 21, pp. 1981-1985, 2010.

[14] B. Moradi, S. Hagmann, A. Zahlten-Hinguranage et al., "Efficacy of multidisciplinary treatment for patients with chronic low back pain: a prospective clinical study in 395 patients," Journal of Clinical Rheumatology, vol. 18, no. 2, pp. 76-82, 2012.

[15] J. Hartvigsen, N. E. Foster, and P. R. Croft, "We need to rethink front line care for back pain," British Medical Journal, vol. 342, article d3260, 2011.

[16] M. Lidegaard, R. B. Jensen, C. H. Andersen et al., "Effect of brief daily resistance training on occupational neck/shoulder muscle activity in office workers with chronic pain: randomized controlled trial," BioMed Research International, vol. 2013, Article ID 262386, 11 pages, 2013.

[17] J. Hardt, "The symptom-check-list-27-plus (SCL-27-plus): a modern conceptualization of a traditional screening instrument," Psycho-Social-Medicine-German Medical Science, vol. 5, doc08, 2008, http://www.egms.de/en/journals/psm/2008-5/ psm000053.shtml.
[18] J. Hardt, "Die symptom-checkliste-27-plus: kreuzvalidierung eines neuen screening-instrumentes," Zeitschrift für Psychologische Medizin, vol. 22, pp. 11-20, 2011.

[19] J. S. Long and J. Freese, Regression Models for Categorical Dependent Variables Using STATA, Stata Press, College Station, Tex, USA, 2003.

[20] StataCorp, Stata Statistical Software: Release 12, StataCorp, College Station, Tex, USA, 12th edition, 2011.

[21] J. Hardt, C. Jacobsen, J. Goldberg, R. Nickel, and D. Buchwald, "Prevalence of chronic pain in a representative sample in the United States," Pain Medicine, vol. 9, no. 7, pp. 803-812, 2008.

[22] H. Neuhauser, U. Ellert, and T. Ziese, "Chronic back pain in the general population in Germany 2002/2003: prevalence and highly affected population groups," Gesundheitswesen, vol. 67, no. 10, pp. 685-693, 2005.

[23] K. Paanalahti, L. W. Holm, C. Magnusson, L. Carroll, and M. Nordin, "The sex-specific interrelationship between spinal pain and psychological distress across time in the general population. Results from the Stockholm Public Health Study," Spine Journal, 2013.

[24] D. Hoy, C. Bain, G. Williams et al., "A systematic review of the global prevalence of low back pain," Arthritis and Rheumatism, vol. 64, no. 6, pp. 2028-2037, 2012.

[25] A. Kędra and D. Czaprowski, "Epidemiology of back pain in children and youth aged 10-19 from the area of the southeast of Poland," BioMed Research International, vol. 2013, Article ID 506823, 6 pages, 2013.

[26] N. Harland and C. G. Ryan, "The value of pain coping constructs in subcategorising back pain patients according to risk of poor outcome," BioMed Research International, vol. 2013, Article ID 898573, 7 pages, 2013.

[27] H. C. Huan, H. J. Chang, K. C. Lin, H. Y. Chiu, and J. H. Chung, "A closer examination of the interaction among risk factors for low back pain," American Journal of Health Promotion. In press.

[28] S. King, C. T. Chambers, A. Huguet et al., “The epidemiology of chronic pain in children and adolescents revisited: a systematic review," Pain, vol. 152, no. 12, pp. 2729-2738, 2011. 


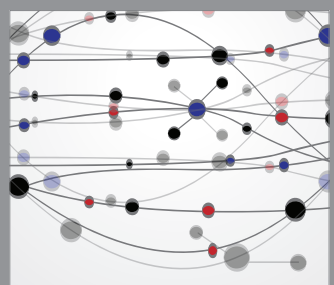

The Scientific World Journal
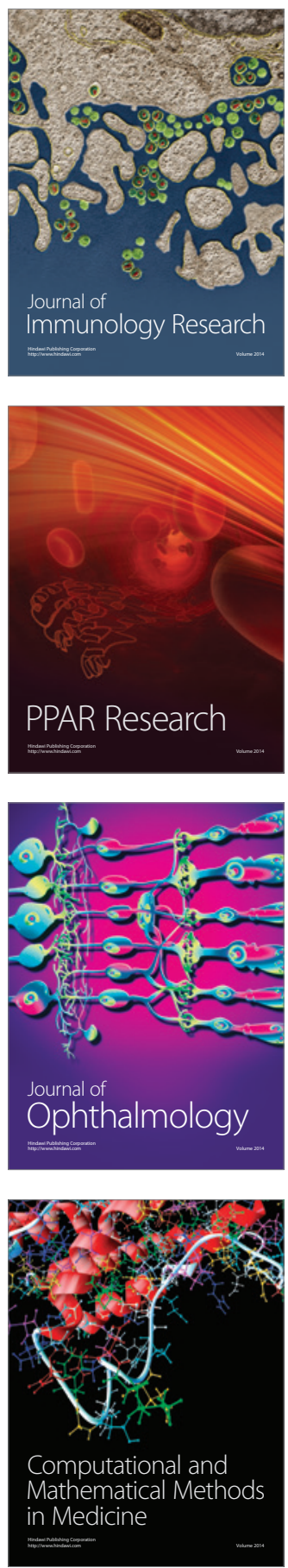

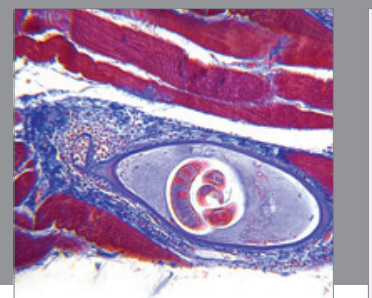

Gastroenterology

Research and Practice
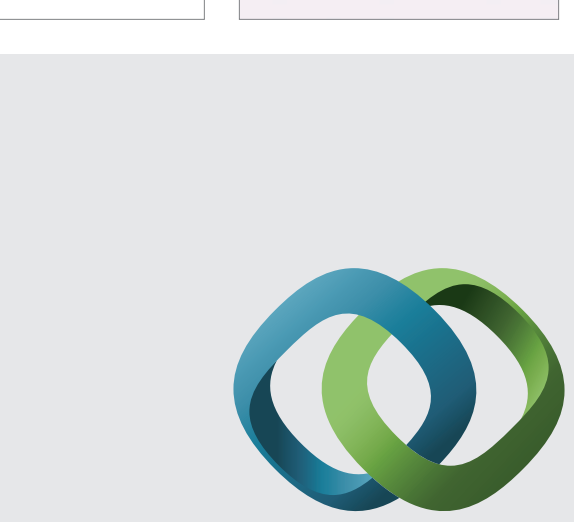

\section{Hindawi}

Submit your manuscripts at

http://www.hindawi.com
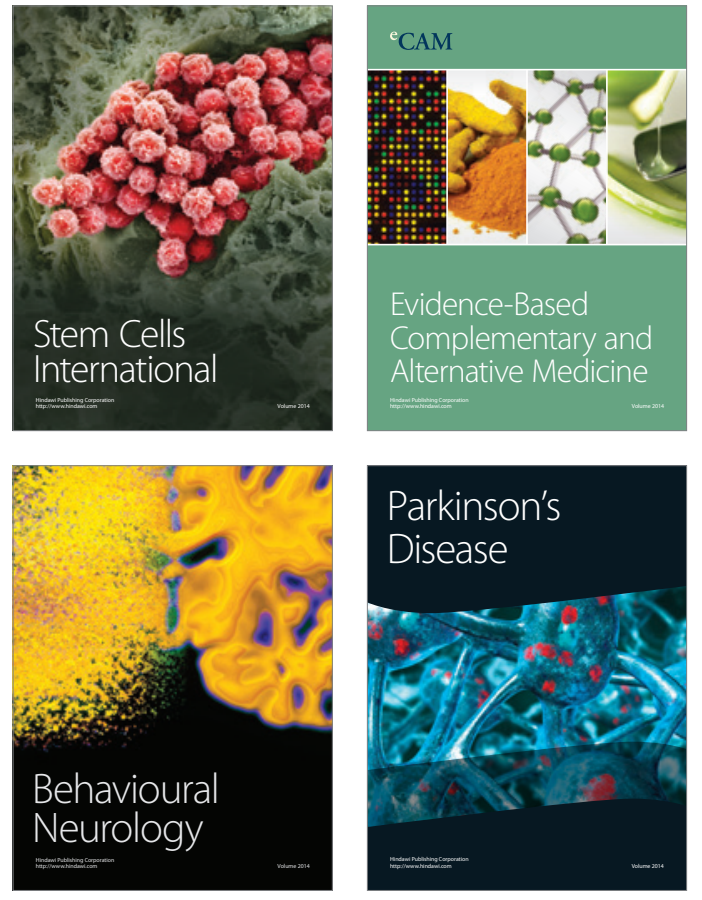
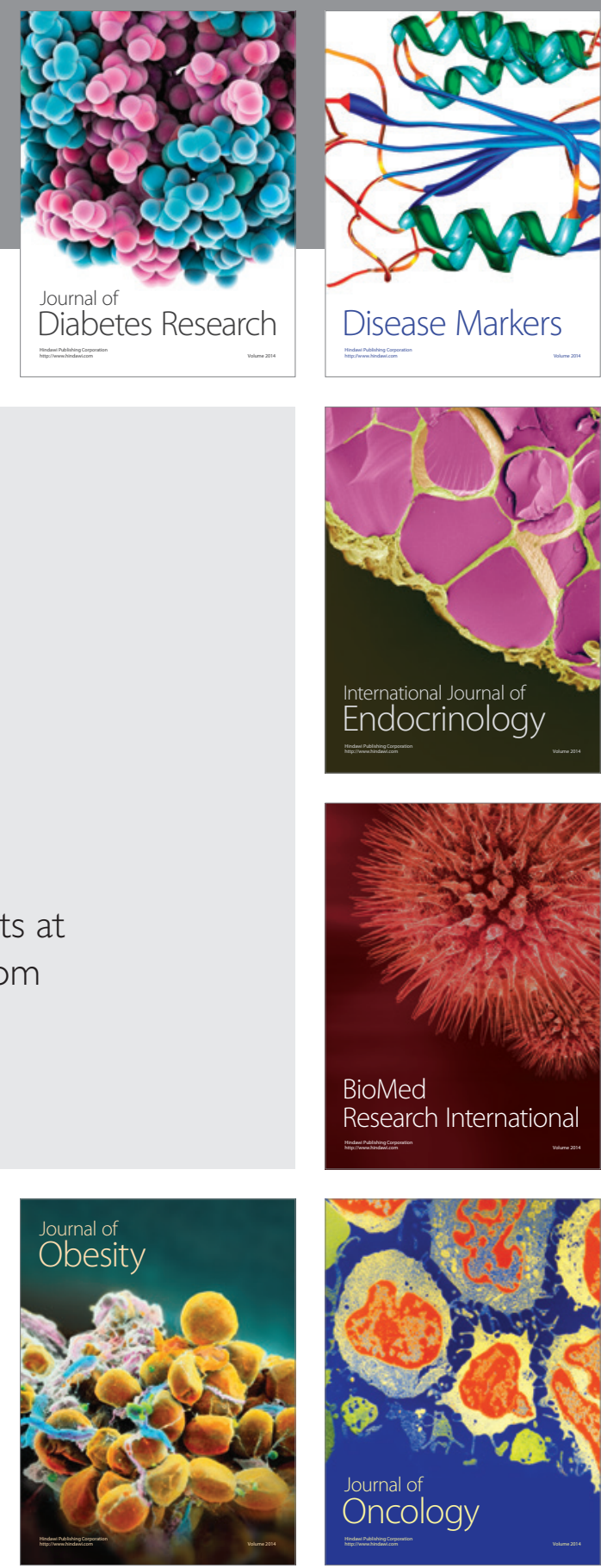

Disease Markers
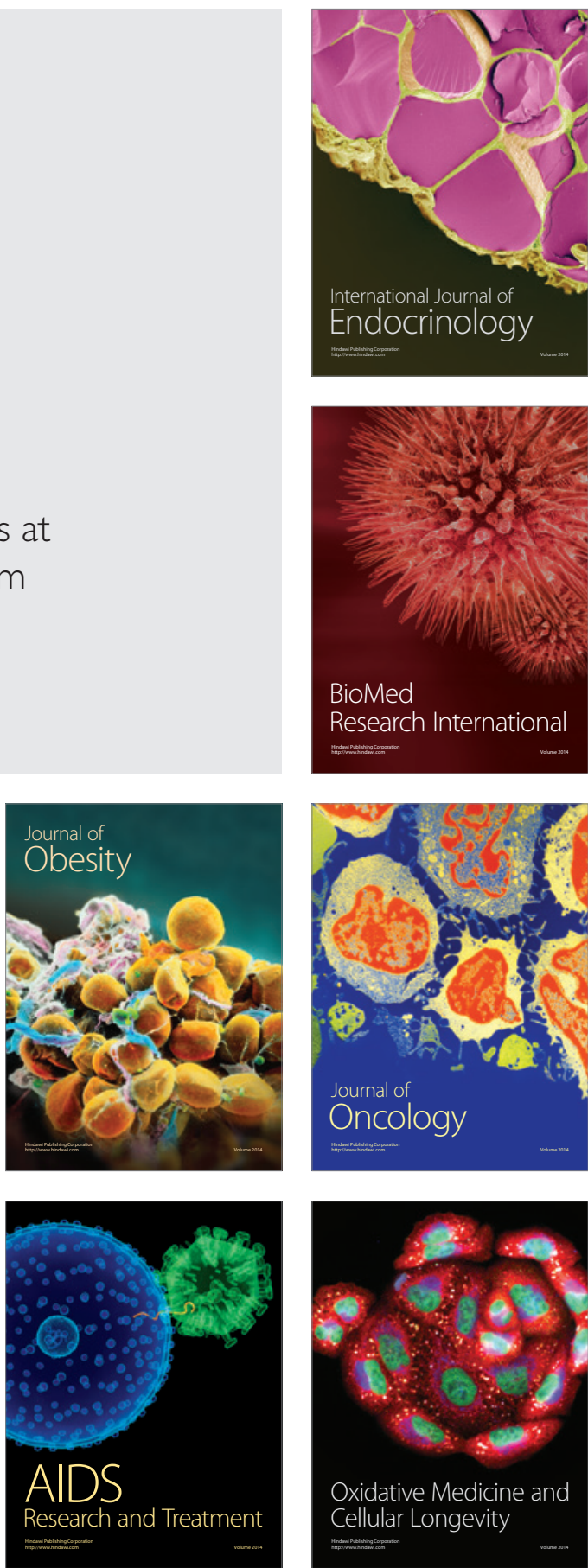